\title{
Technical Note \\ Monitoring and Analysis of Geotemperature during the Tunnel Construction
}

\author{
Tao Wen ${ }^{1,2}$, Zheng $\mathrm{Hu}^{3,4, *}$, Yankun Wang ${ }^{2}$, Zihan Zhang ${ }^{2}$ and Jinshan Sun ${ }^{1, *(D)}$ \\ 1 State Key Laboratory of Precision Blasting, Jianghan University, Wuhan 430056, China; \\ wentao200840@yangtzeu.edu.cn \\ 2 School of Geosciences, Yangtze University, Wuhan 430100, China; ykwang@yangtzeu.edu.cn (Y.W.); \\ 201900521@yangtzeu.edu.cn (Z.Z.) \\ 3 Power China Guiyang Engineering Corporation, Limited, Guiyang 550081, China \\ 4 Guizhou BIM Engineering and Technology Research Center, Guiyang 550081, China \\ * Correspondence: huzheng_gyy@powerchina.cn (Z.H.); sunjinshan@cug.edu.cn (J.S.)
}

check for updates

Citation: Wen, T.; Hu, Z.; Wang, Y.; Zhang, Z.; Sun, J. Monitoring and Analysis of Geotemperature during the Tunnel Construction. Energies 2022, 15, 736. https://doi.org/ $10.3390 /$ en15030736

Academic Editors: Rao Martand Singh and Carlo Roselli

Received: 4 November 2021

Accepted: 13 January 2022

Published: 20 January 2022

Publisher's Note: MDPI stays neutral with regard to jurisdictional claims in published maps and institutional affiliations.

Copyright: (c) 2022 by the authors. Licensee MDPI, Basel, Switzerland. This article is an open access article distributed under the terms and conditions of the Creative Commons Attribution (CC BY) license (https:// creativecommons.org/licenses/by/ $4.0 /)$.

\begin{abstract}
High geotemperatures are encountered during tunnel construction in areas with complex geological structures, which can seriously affect personnel and equipment in the process of tunnel construction and operation. The Nige tunnel, a deep-buried extra-long tunnel, was selected to monitor the geotemperature during construction. The air, rock, and water temperatures during the tunnel construction were measured at the tunnel face, and the actual temperatures of the rock or water body at the tunnel face were measured by advanced drilling. The variation trends of the water temperature, air temperature, and flow of water with the tunnel mileage were analyzed. The differences in three measured rock temperatures in three advanced drillings were revealed. The results showed that the Nige tunnel had a maximum water temperature of $63.4^{\circ} \mathrm{C}$, maximum rock temperature (Rock T) of $88.8^{\circ} \mathrm{C}$, and maximum air temperature (Air T) of $56.4^{\circ} \mathrm{C}$. Increasing trends of the air, rock, and water temperatures with the tunnel's horizontal distance and the buried depth (vertical depth) were obvious, and the geotemperature gradient was approximately $7.6{ }^{\circ} \mathrm{C}$ per $100 \mathrm{~m}$. Additionally, the variation laws of the construction ambient temperature with time in a complete construction cycle showed four stage characteristics, and each stage presented different mathematical relationships. These findings will provide guidance for the construction of high geotemperature tunnels in future.
\end{abstract}

Keywords: construction; high geotemperature tunnel; air temperature; rock temperature; variation laws

\section{Introduction}

With the rapid development of China's transportation network, highway and railway transportation began to expand to high mountain and canyon areas, with high construction difficulty and complex geological conditions [1,2]. Tunnel engineering has become an important part of transportation construction and is also gradually developing towards deep-buried and long tunnels [3]. Therefore, a large number of tunnel projects with high buried depths and high geotemperatures have been undertaken or proposed [4]. In this study, the buried depth of the tunnel refers to the vertical distance from the top of the tunnel excavation section to the land surface. The horizontal distance of the tunnel refers to the horizontal distance from the starting point of the tunnel to the excavation section. The construction and operation of tunnels are being confronted with new situations and challenges. For example, the Sichuan Tibet Railway, which is currently under construction, is particularly important for national transportation network construction and homeland security. However, the railway passes through extremely complex structural fault areas, and many deep-buried extra-long tunnels will need to be built. Thus, the problems of high geotemperatures will likely be encountered in these tunnels. High-geotemperature tunnels 
are important in underground engineering and geotechnical engineering [5]. Therefore, it is necessary to study the temperature field of high geotemperature tunnels.

To date, attempts to analyze the geotemperature field of tunnels based on field investigations have made some progress [6-10]. As a pioneering definition, when the buried depth of the tunnel is too large, or the temperature of the surrounding rock affected by magmatic activity is more than $30^{\circ} \mathrm{C}$, this kind of tunnel is called a high geotemperature tunnel [11]. Generally speaking, a high geotemperature includes a high rock temperature and high water temperature. In practical engineering, it may only be a high rock temperature. The heat damage caused by the high geotemperature of tunnels is becoming more and more problematic [6]. Due to excavation unloading under high geostress, rock bursts often occur during the tunnel excavation [12,13]. A rock burst is a kind of dynamic instability geological disaster in a high geostress area and produces the phenomena of bursting, loosening, spalling, ejection, and even throwing of rock blocks [14]. Heat damage aggravates the occurrence of rock burst. Heat damage in tunnels not only affects construction progress but also impacts the working environment and affects the structural stability. However, due to the traffic and construction conditions in remote plateaus and mountainous areas, the traditional drilling and geophysical exploration methods are often difficult to carry out. Therefore, in the tunnel survey stage, obtaining a relatively accurate prediction and classification of the heat damage of the tunnel based on the temperature of the surrounding rock has become an engineering problem $[10,15,16]$. In an area that cannot be completely assessed by drilling and geophysical exploration, other means, such as numerical simulation and theoretical speculation, must be utilized when predicting the tunnel heat damage based on limited data.

Temperature effects have a significant influence on rock bursts at high geotemperatures [2]. Therefore, it is necessary to study the laws of rock bursts and their mechanism under thermomechanical coupling [11]. Moreover, the evolution law of the geotemperature of the tunnel plays an important role in revealing the mechanism of the rock burst. The influences of the geotemperature on the rock can be summarized by the following two aspects. The first is the influence of the temperature on the basic mechanical parameters of the rock $[17,18]$. Most studies are based on laboratory mechanical test results, which vary the laws of the mechanical parameters of the rock with the temperature under hightemperature conditions $[1,19]$. The other aspect is the change in the failure modes of the rock caused by the temperature [20-22]. According to laboratory mechanical tests, CT scanning, and acoustic emission monitoring methods, most studies have found that an increase in the temperature leads to the transformation of the rock from brittleness to ductility, and these studies have revealed the law of strength decreasing with time and the micro-failure mechanism of the rock.

A lot of research has been undertaken on the influences of the geotemperature field of tunnels on rock bursts $[2,8,11]$. Although the expressions of some geotemperature fields have a certain physical significance, the results may be contradictory due to a lack of sufficient monitoring data when revealing the geotemperature field of the tunnels. The characteristics of the tunnel geotemperature during construction are significant and crucial for geotemperature prediction and rock burst analysis. In this study, geotemperature tests during the construction were conducted to provide the basis for analyzing the variation laws of the geotemperature of the tunnel face. Afterwards, the variation trends of the water temperature, air temperature, and rock temperature based on the horizontal distance of the tunnel were analyzed. Subsequently, the differences of the three measured rock temperatures in three advanced drillings were revealed. Finally, the air temperature of the tunnel construction area was tested continuously for six construction cycles, and the mathematical relationship between the air temperature and time was proposed.

\section{Tunnel Engineering Geological Conditions}

The Nige tunnel, which has left and right tunnels, is located in the middle of the mountain near Kele Village, Jiasha Town, Gejiu City, Honghe Prefecture. The total length 
of the left tunnel is $3366 \mathrm{~m}$. The design stake number of the starting point in the left tunnel is LZ5K44+300, and its elevation is $1026.8 \mathrm{~m}$. Similarly, the design stake number of the terminal point in the left tunnel is LZ5K47+666, and its elevation is $958.9 \mathrm{~m}$. The total length of the right tunnel is $3351 \mathrm{~m}$. The design stake number of the starting point of the right tunnel is LK44+315, and its elevation is $1026.8 \mathrm{~m}$. The design stake number of the terminal point of the right tunnel is LK47+666, and its elevation is $959.2 \mathrm{~m}$. Additionally, the maximum buried depth of the tunnel is $639 \mathrm{~m}$. Therefore, the tunnel can be considered a deep-buried extra-long tunnel, as shown in Figure 1.

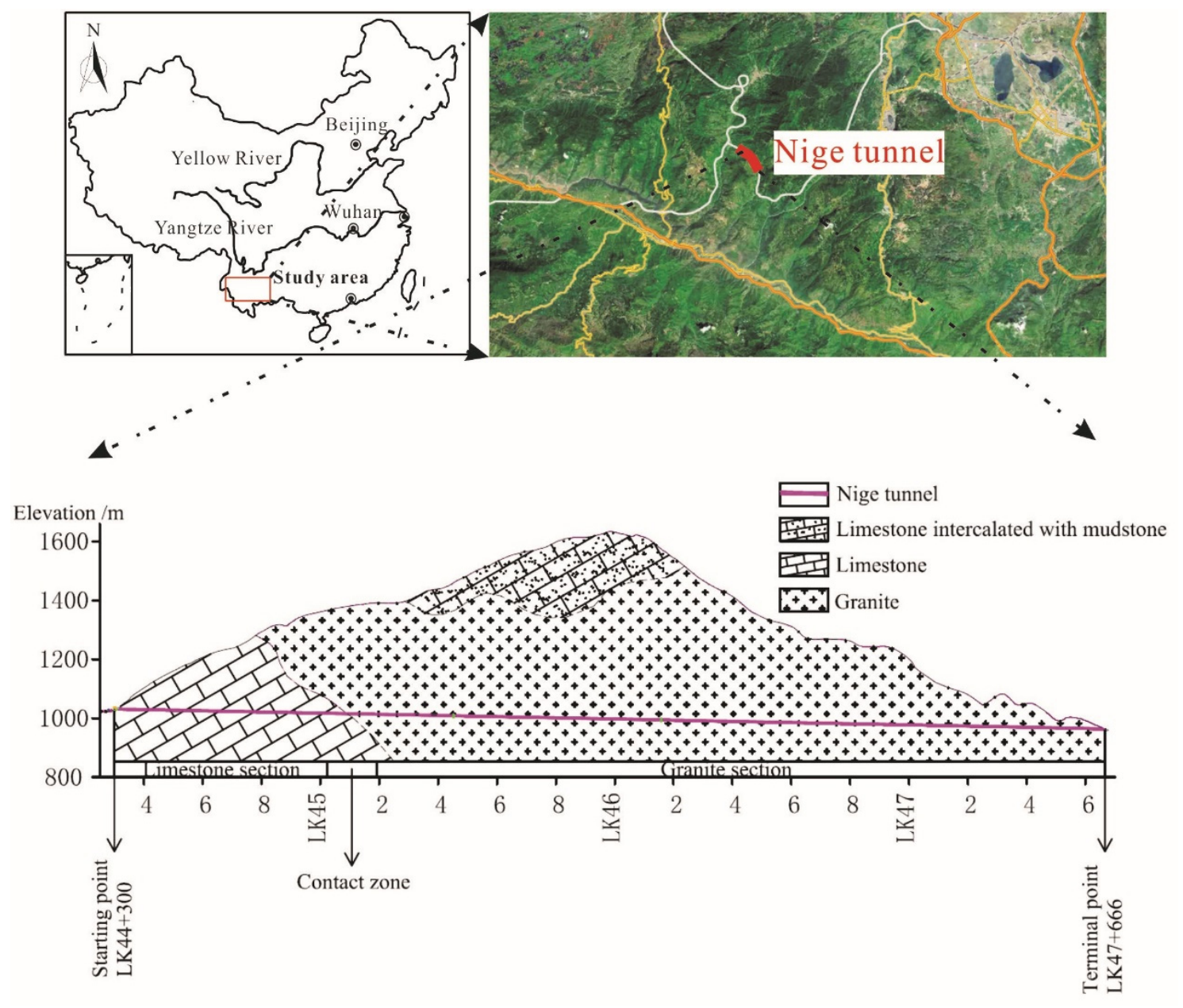

Figure 1. Geographical location and cross section of the Nige tunnel.

The Nige tunnel crosses high and middle mountain terrain, with a distribution elevation of $959 \mathrm{~m}$ to $1641.6 \mathrm{~m}$, and the relative height difference is $682.6 \mathrm{~m}$. The topographic slope at the tunnel entrance section is relatively steep, with a slope of $30^{\circ}$ to $35^{\circ}$. The slope near the tunnel is distributed with Quaternary loose eluvial diluvium, on which the vegetation, mainly shrubs, is well developed, and the bedrock is locally outcropped. The topographic slope at the tunnel exit section is $20^{\circ}$ to $25^{\circ}$. Simultaneously, the slope is also distributed with Quaternary loose eluvial diluvium, and the vegetation on it is densely developed. From the high elevation to the low elevation in Figure 1, the strata in the Nige tunnel site are Quaternary eluvial diluvium and Yanshanian granite, which is the lower member of the Gejiu formation of the Middle Triassic system. The lithology is a light gray thin layer and a medium-thick layer of dolomite and limestone. Since the Paleozoic, the tunnel site has experienced many tectonic disturbances, so a complex geological structure occurs in the tunnel. 


\section{Geotemperature Test Scheme and Instrument Selection}

\subsection{Geotemperature Test Scheme}

The purpose of the geotemperature test during construction is to provide the basis for construction cooling and geotemperature prediction at the frontage of the tunnel face. The main contents of the test include the following two aspects.

(a) The air, rock, and water temperatures in the construction area were measured at the tunnel face. As shown in Figure 2, the rock temperature was measured at 5-8 places at different positions in the tunnel face, and then the maximum and average values of the rock temperature were recorded. Additionally, the water temperature was measured at 2-3 places near the tunnel face, and the maximum and average values of the water temperature were also recorded. The flow of the water of the tunnel was also measured. In addition, the air temperature was measured at 3-5 places at different heights within $10 \mathrm{~m}$ of the tunnel face, and the maximum and average values of the air temperature were recorded. The variation laws of the rock temperature and the water temperature with the horizontal distance and the buried depth of the tunnel were analyzed. Then, the influence of the flow of the water, the water temperature, and tunnel ponding on the air temperature of the tunnel was revealed.

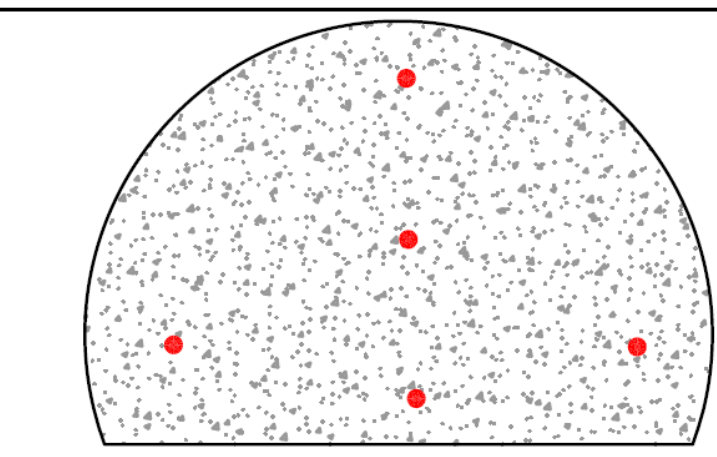

(a)

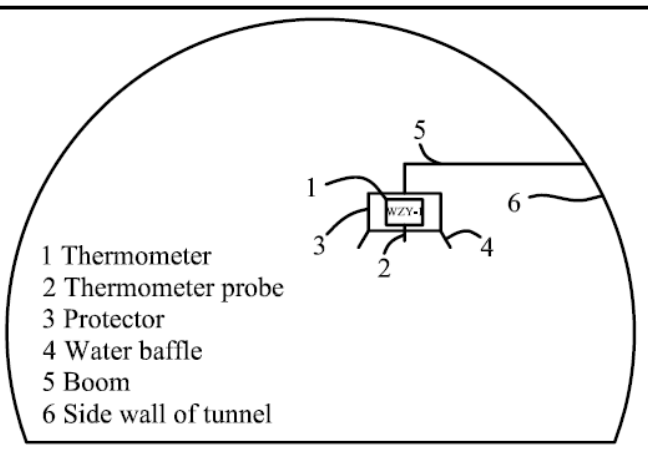

(b)

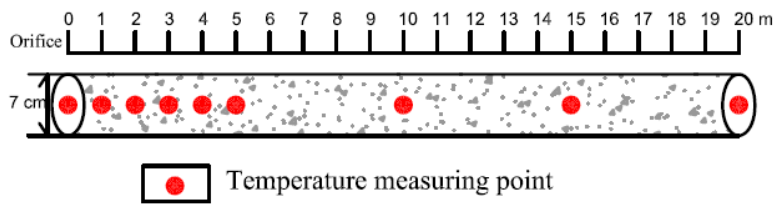

(c)

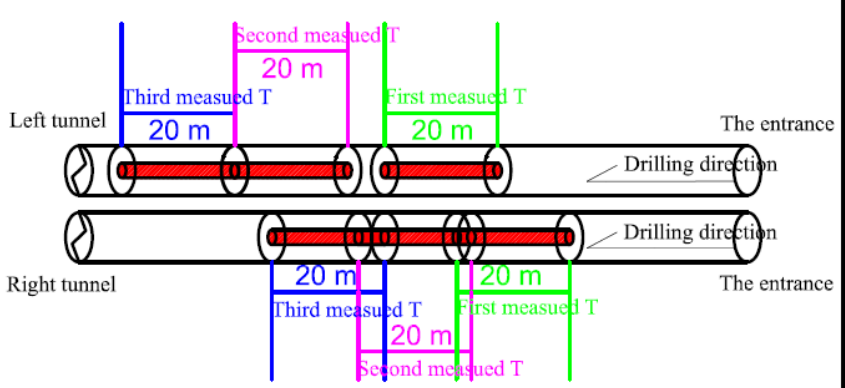

(d)

Figure 2. Layout of temperature measuring points and their installation: (a) Layout of temperature measuring point in tunnel face; (b) Layout of air temperature measuring device for each construction link; (c) Layout of temperature measuring point in advance drilling; (d) Layout of advanced drilling.

(b) In order not to affect water detection and drainage, inclined drilling with an upward angle of $5-15^{\circ}$ was utilized for the measurement of the water temperature. However, horizontal drilling was used for the measurement of the rock temperature. Therefore, the actual temperatures of the surrounding rock or the water body before the excavation were measured by advanced drillings, as shown in Figure 2c. The aperture of the advanced drilling was $7 \mathrm{~cm}$, and the range of the lengths was $20-30 \mathrm{~m}$. The temperature measurement points in the advanced drillings were properly densified near the hole opening, with a spacing of 1-5 $\mathrm{m}$. The variation characteristics of the rock temperature in the advanced drillings with the hole depth were analyzed. In the left and right tunnels, three temperature 
measurements from the advanced drillings were made in the construction section of the tunnel exit, as shown in Figure $2 \mathrm{~d}$. When monitoring the rock temperature, the thermometer probe was close to the wall of the tunnel. The thermometer probe was placed inside the tunnel when monitoring the air temperature.

\subsection{Instrument Selection for Geotemperature Testing}

The WZY-1 temperature recorder was selected as the thermometer; it is produced by Beijing Tianjianhuayi Instrument Technology Development Co., Ltd in Beijing, China. The size of the thermometer is $98 \mathrm{~mm}$ in length, $49 \mathrm{~mm}$ in width, and $25 \mathrm{~mm}$ in height, with a measurement range of -50 to $100{ }^{\circ} \mathrm{C}$ and measurement accuracy of $\pm 0.3^{\circ} \mathrm{C}$. The maximum recording number of the thermometer is 30,000 points. Additionally, the instrument was calibrated before the measurement. In this study, the temperature recording time interval of the thermometer was set to 5-10 $\mathrm{min}$, and the monitoring time of the rock temperature was $24 \mathrm{~h}$ Simultaneously, the change in temperature outside the tunnel was also monitored. The thermometer and the monitoring site photos are shown in Figure 3.

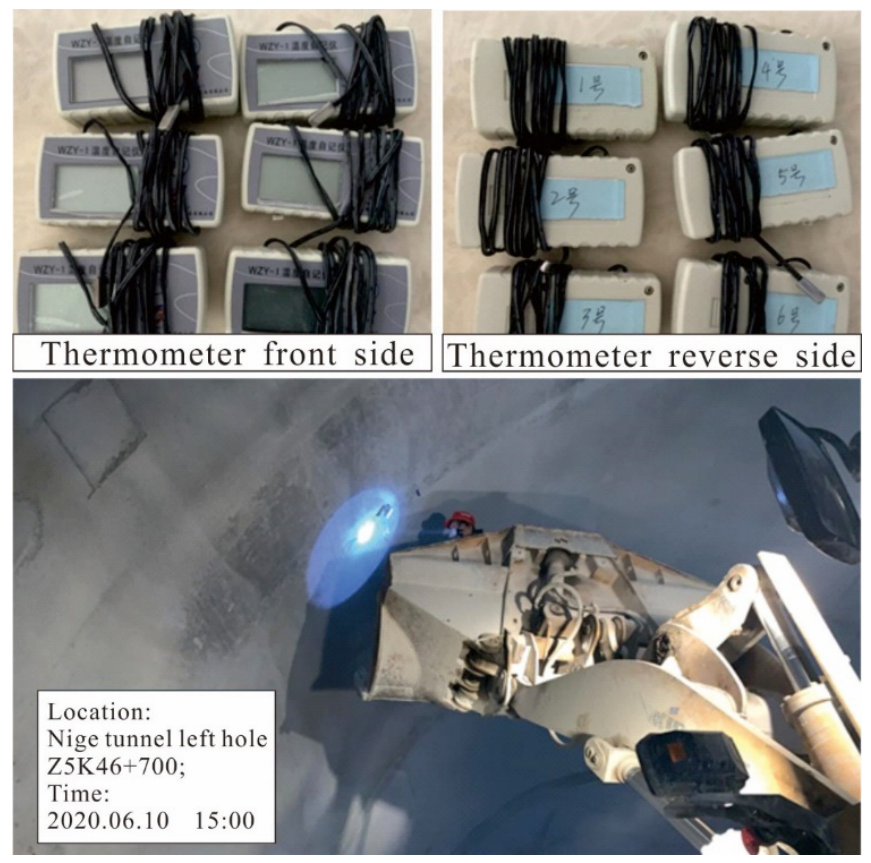

Figure 3. Thermometer and its field application.

\section{Analysis of the Geotemperature Test Results}

\subsection{Variation Laws of the Geotemperature in the High Water Temperature Section}

Figure 4 presents the variation trends of the water temperature, air temperature, buried depth, and flow of the water with the tunnel mileage. In this Figure, 45,000 on the abscissa represents the design stake number LK45+000. As shown in Figure 4, the water temperature showed an upward trend with the horizontal distance and the buried depth of the tunnel. Obviously, the air temperature was affected by the water temperature, the flow of the water, and the tunnel ponding. The flow of the water had a positive correlation with the water temperature. The water temperature and the flow of the water are usually high because the tunnel passes through large faults and contact zones. Similarly, the air temperature had the same relationship with the water temperature. The water temperature was generally $8-12{ }^{\circ} \mathrm{C}$ higher than the air temperature. Near the contact zone between the limestone and the granite, the flow of the water increased, with values of 9-11 L/s, and the water temperature reached a maximum value of $53.9^{\circ} \mathrm{C}$ based on the data obtained during the temperature measurement period. The air temperature is controlled by both the water temperature and the flow of the water, and it also reached a high value. In the process of ascending intrusion of the magma, the volume of the magma shrinks sharply 
due to condensation. A large fracture-type groundwater passage near the contact zone is prone to forming, which becomes an important passage for the infiltration of the shallow water body and the circulation of the deep thermal anomaly body. Therefore, both the water temperature and the flow of the water were relatively large.

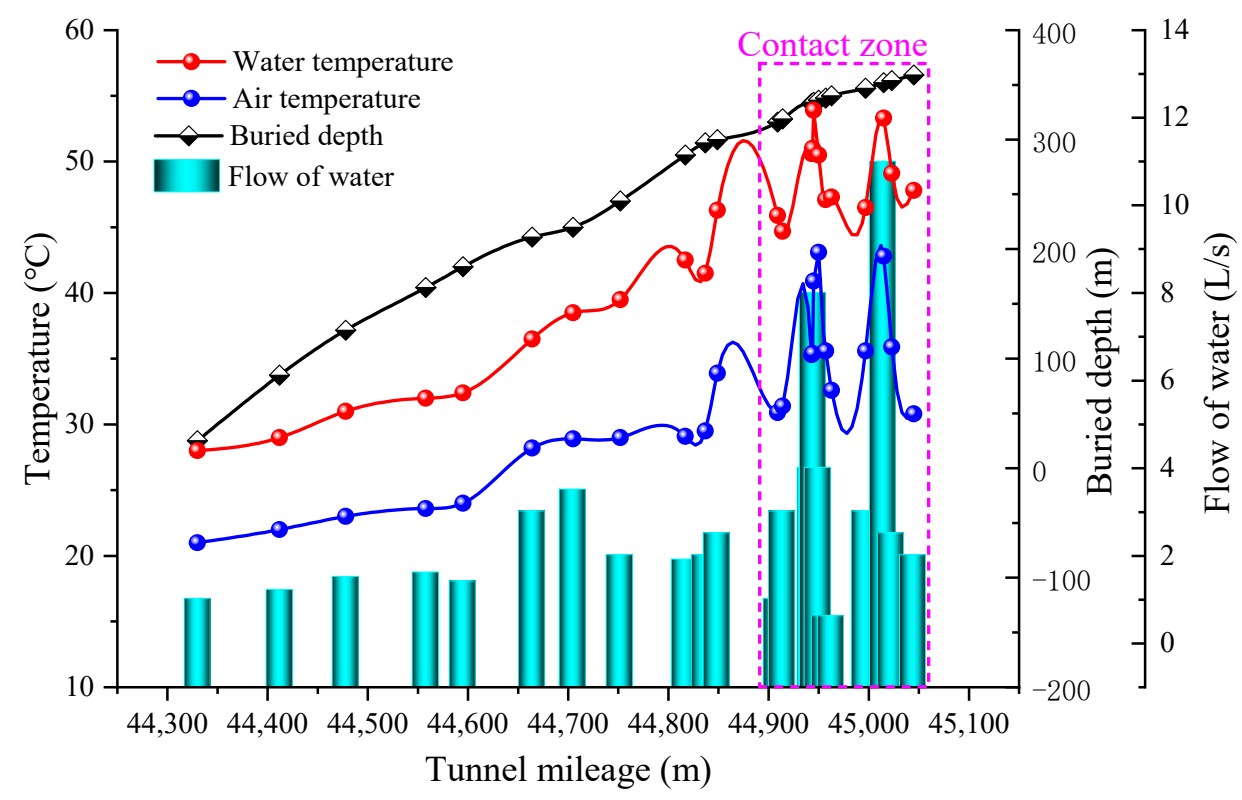

Figure 4. Variation curves of the water temperature, air temperature, buried depth, and flow of the water with tunnel mileage.

Figure 5 shows the monitoring data of the temperature within a length of about $500 \mathrm{~m}$ of the tunnel entrance in the early stage of construction. Except at the tunnel entrance, the air temperature in the left and right tunnels increased with the increase in the tunnel's horizontal distance, showing a good linear relationship. Moreover, the surface temperature of the rock also increased as a whole, and there was a sudden rise near the tunnel face. On the contrary, there was a sudden rise in the surface temperature of the rock near the tunnel entrance. This is because deep and large faults are located in the tunnel entrance. The deep thermal anomalous bodies migrate upward through the heat conduction channels, such as deep fault structures. Thus, there exists a large number of water accumulation areas at the entrance of the tunnel. To sum up, the high water temperature causes the air temperature and the surface temperature of the rock to rise. The air relative humidity in the left tunnel increased first and then decreased due to the increase in the geotemperature, and its maximum value reached about $90 \%$. Simultaneously, the air relative humidity in the right tunnel basically presented an increasing trend with the horizontal distance, and its maximum value also reached approximately $90 \%$. This is because the relative humidity is closely related to the flow of the water. When the left tunnel was constructed in the tunnel face, the flow of the water was reduced, and exhaust measures were taken, while the right tunnel does not perform relevant operations. 

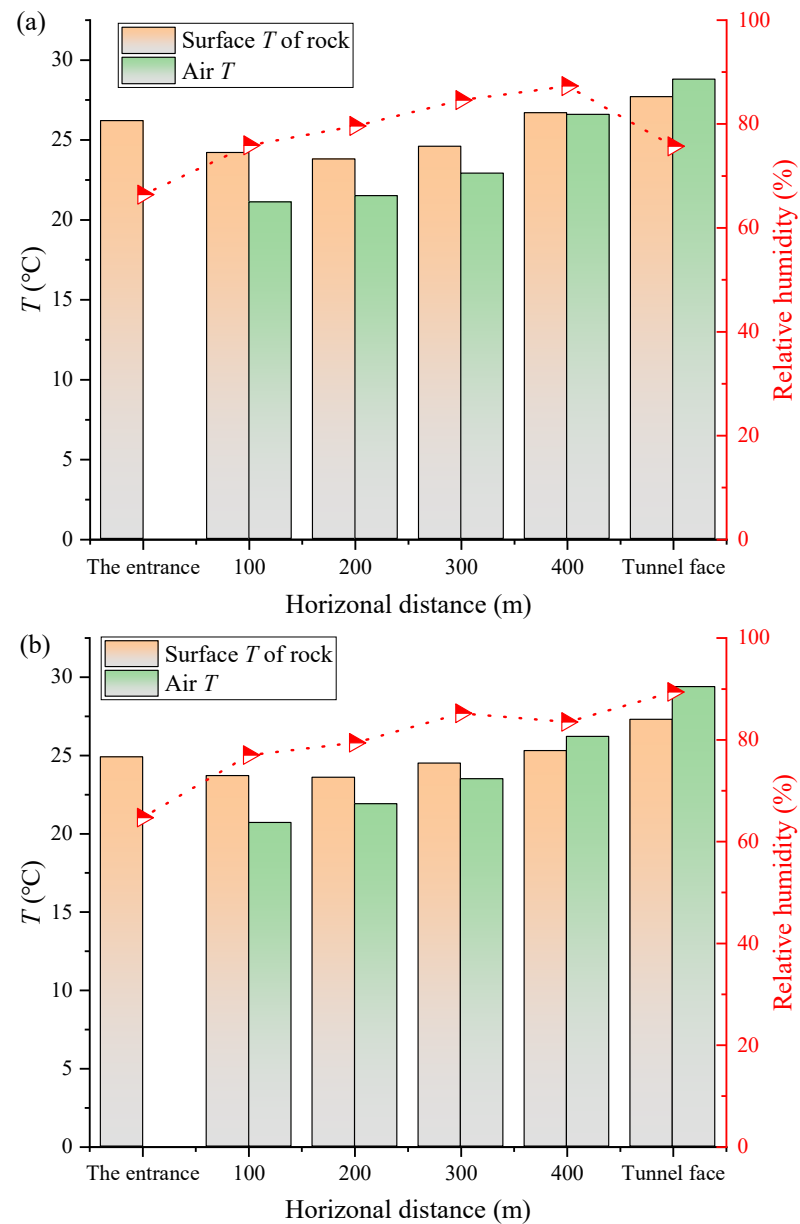

Figure 5. Temperature and relative humidity distribution characteristics at different horizontal distances in the tunnel, in which $T$ is the abbreviation for temperature: (a) left tunnel; (b) right tunnel.

The groundwater in the limestone section of the tunnel can be divided into the loose layer pore water, the bedrock fissure water, and carbonate fissure water. Due to the high and steep terrain of the tunnel area, the dissolution phenomenon of the rock mass in the limestone section is locally developed. Therefore, the storage conditions of the groundwater are poor, and the groundwater is discharged rapidly after being replenished by atmospheric precipitation. During the tunnel excavation in the limestone section, the groundwater was mainly dripping and linear water. Specifically, there may be strand water and mud gushing along the structural contact zone in flood season, so the groundwater had a certain impact on the excavation of the tunnel. Thus, tunnel water gushing may have occurred along the fracture zone during tunnel excavation, leading to ponding in the tunnel. For the tunnel ponding water, some ponding water exhibited a high water temperature, as shown in Figure 6. According to the figure, there exists a large number of water accumulation areas in the entrance of the right tunnel, and the temperature of the ponding water is even higher than the air temperature and surface temperature of the rock. The temperature of the ponding water was above $30^{\circ} \mathrm{C}$, and even up to $40^{\circ} \mathrm{C}$. As the time of the ponding water's exposure to the air increases, the water temperature dissipates heat and diffuses it into the air, resulting in an increase in the ambient temperature in the tunnel [8]. Therefore, not only the water temperature affects the ambient temperature, but also the water accumulation area influences the construction ambient temperature. Therefore, during construction, the tunnel ponding water must be discharged in time to achieve a cooling effect. 


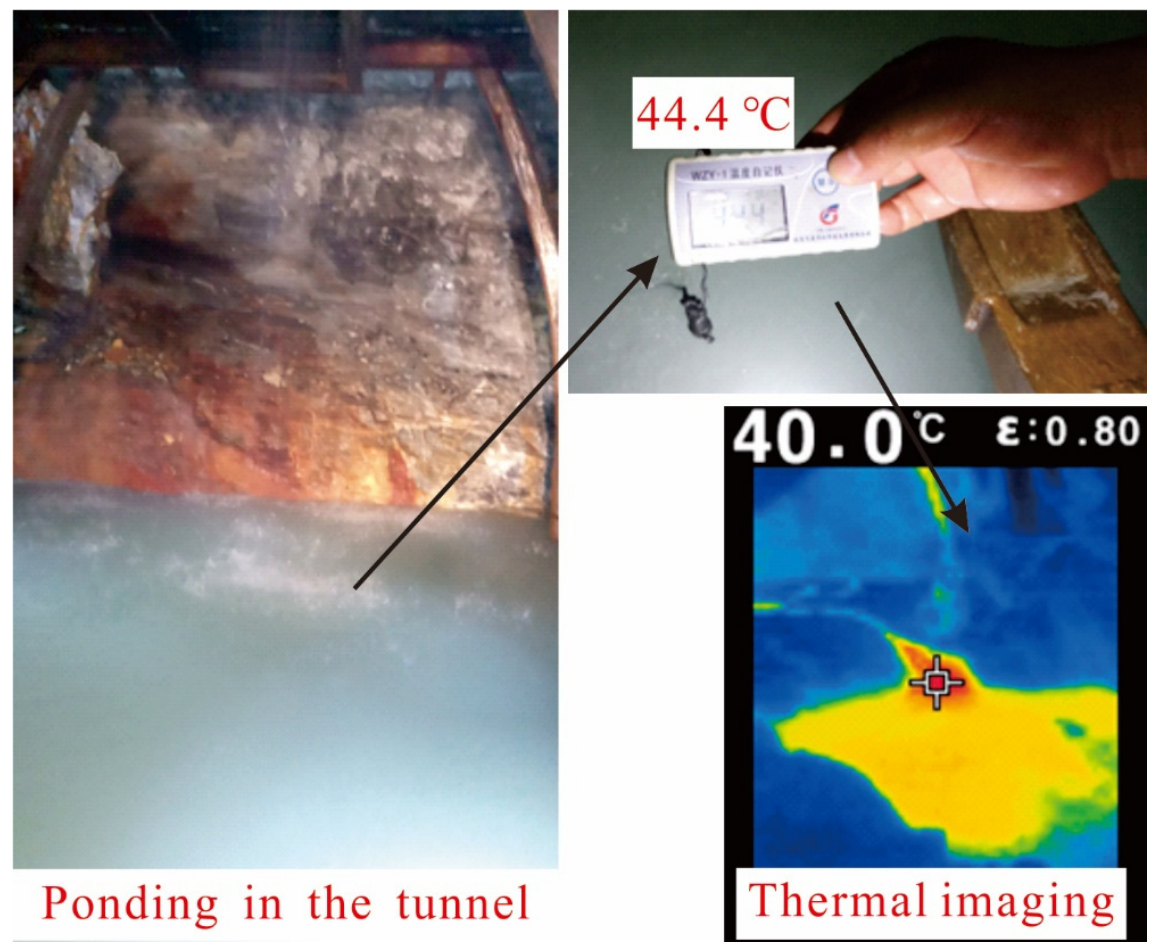

Figure 6. The tunnel ponding and its thermal imaging.

\subsection{Variation Laws of the Geotemperature in the High Rock Temperature Section}

The results of the geotemperature in the high rock temperature section are shown in Figure 7. The vertical buried depth of the tunnel in the section increased from $167 \mathrm{~m}$ to $635 \mathrm{~m}$, and the rock temperature increased from $52.6^{\circ} \mathrm{C}$ to $88^{\circ} \mathrm{C}$ and the air temperature from $35.2{ }^{\circ} \mathrm{C}$ to $56.4^{\circ} \mathrm{C}$. Therefore, the geotemperature gradient reached $7.6^{\circ} \mathrm{C}$ per $100 \mathrm{~m}$, and the difference between the rock temperature and the air temperature was approximately $25-30{ }^{\circ} \mathrm{C}$. This difference is because the monitored tunnel section was in the granite section. The granite section is mainly characterized by a high rock temperature, and the geothermal energy is mainly transmitted through structural fractures. Additionally, both the rock temperature and the air temperature showed upward trends with the increase in the vertical buried depth and the horizontal distance of the tunnel. The difference between the rock temperature and the air temperature gradually increased with the drilling direction. Therefore, the farther away from the tunnel entrance or exit, the higher the internal rock temperature. Moreover, the increase rate of the rock temperature was higher than that of the air temperature. However, the increase rate of the rock temperature slowed when the tunnel was excavated to the mileage of LK46+500, and the difference remained within $5{ }^{\circ} \mathrm{C}$. The possible reason for this is that the heat dissipation and cooling effect in the tunnel decreases with the increase in the horizontal distance of the tunnel. 


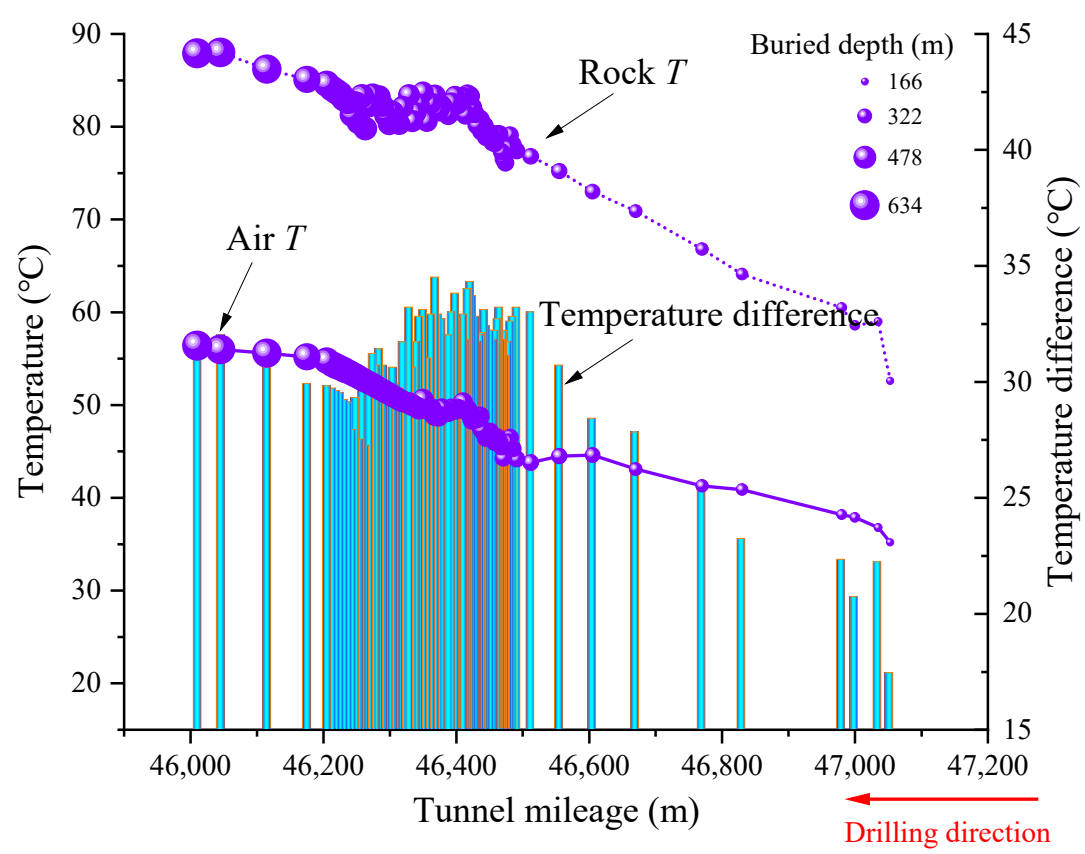

Figure 7. Variation curves of the rock temperature and the air temperature with the tunnel mileage and the buried depth, in which $\mathrm{T}$ is the abbreviation of temperature.

\subsection{The Variation Characteristics of the Rock Temperature and the Air Temperature with the Horizontal Distance under Various Construction Conditions}

The construction procedure of the tunnel included excavation, blasting, scarfing cinder, and other steps. It also involved construction suspensions caused by uncontrollable factors. Therefore, three construction conditions, namely normal construction conditions, blasting conditions, and suspended construction conditions, were considered in this study. Normal construction conditions refer to the lack of a blasting effect, but the mechanical activities and workers' activities have an impact. Blasting conditions refer to the conditions for a short time after tunnel blasting. The heat dissipation of newly blasted surrounding rock occurs under these conditions. Suspension construction conditions refer to when construction is suspended for more than $24 \mathrm{~h}$. Both the rock temperature and the air temperature measurement results under these three construction conditions were organized, as shown in Figure 8. It can be seen from the figure that under normal construction conditions, both the rock temperature and the air temperature increased with the horizontal distance of the tunnel. Near the tunnel face, the rising rates of the two temperatures increased, and the rock temperature increased faster than the air temperature. Under blasting conditions, both the rock temperature and the air temperature of the right tunnel increased with the horizontal distance after blasting. In addition, the two temperatures of the right tunnel under blasting conditions were about $5-10{ }^{\circ} \mathrm{C}$ higher than those of the left tunnel under normal construction conditions, especially in the area close to the tunnel face. The reason for this is that the tunnel face is close to the blasting point and receives the strongest energy impact. Under suspended construction conditions, the variation characteristics of the temperature of the left and right tunnels were basically the same, showing upward trends with the horizontal distance of the tunnel. After heat exchange, the temperature of the tunnel gradually tended to balance under suspended construction conditions. Specifically, the rock temperature of the right tunnel was higher than that of the left tunnel at the same horizontal distance of the tunnel. However, there was little difference between the air temperature of the left tunnel and that of the right tunnel. Except for individual horizontal distances, both the rock temperature of the left tunnel and that of the right tunnel were higher than the air temperature at the same horizontal distance of the tunnel. 

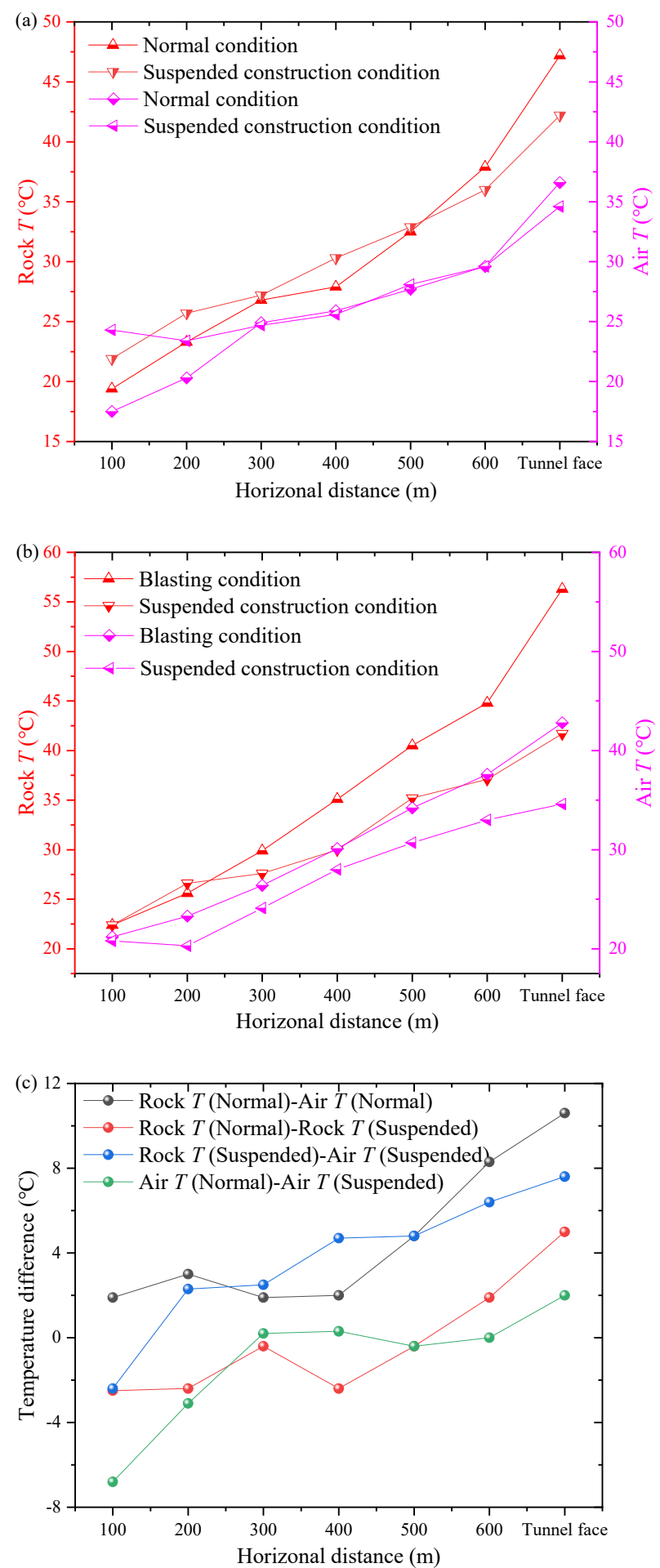

Figure 8. Cont. 


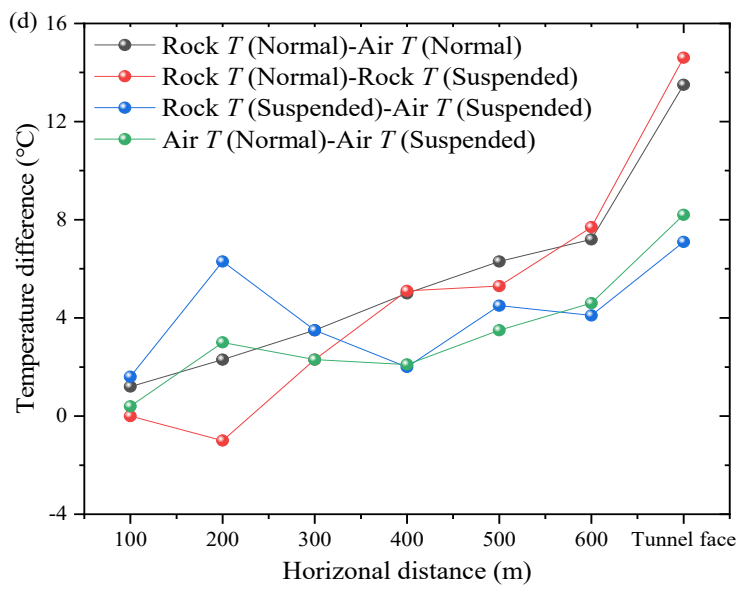

Figure 8. Variation curves of the air temperature and rock temperature with the horizontal distance under various construction conditions, in which $\mathrm{T}$ is the abbreviation of temperature: (a) Variation curves in the left tunnel; (b) variation curves in the right tunnel; (c) temperature difference in the left tunnel; (d) temperature difference in the right tunnel.

\subsection{Results and Analysis of the Rock Temperature Measurement in Advanced Drilling}

The measurement data of the rock temperature in three advanced drillings is shown in Figure 9. It can be seen from the figure that for the left tunnel, the difference of the first measured rock temperature is the largest at both ends of the advanced drilling, with a difference of about $16^{\circ} \mathrm{C}$. The difference of the second measured rock temperature was the smallest, at about $9{ }^{\circ} \mathrm{C}$. For the left tunnel, the third measured rock temperature at the beginning of the advanced drilling was the largest, while the second measured rock temperature was the smallest. For the right tunnel, the first measured rock temperature had the greatest difference at both ends of the advanced drilling, with a difference of about $18^{\circ} \mathrm{C}$. The difference of the second measured rock temperature at both ends was about $14^{\circ} \mathrm{C}$. Similarly, the third measured rock temperature had basically similar laws. Furthermore, for the right tunnel, the first and second measured rock temperatures at the beginning of the advanced drilling were slightly greater than the third measured rock temperature. The second and third measured rock temperatures at the end of the advanced drilling were slightly greater than the first measured rock temperature. Overall, for the left and right tunnels, the change trends of the rock temperature in the advanced drillings were basically the same. The rock temperature increased sharply in the range of $0-2 \mathrm{~m}$ hole depth and tended to be stable in the range of $2-20 \mathrm{~m}$ hole depth. The difference between the rock temperature at the beginning and end of the advanced drilling was about $10-15^{\circ} \mathrm{C}$, so the actual temperature of the rock mass was different from the surface temperature of the rock, and the difference was relatively large. Therefore, the temperature value in a hole with a depth of more than $2 \mathrm{~m}$ can be regarded as the rock temperature, and the temperature measured inside the blast hole can represent the actual rock temperature. 

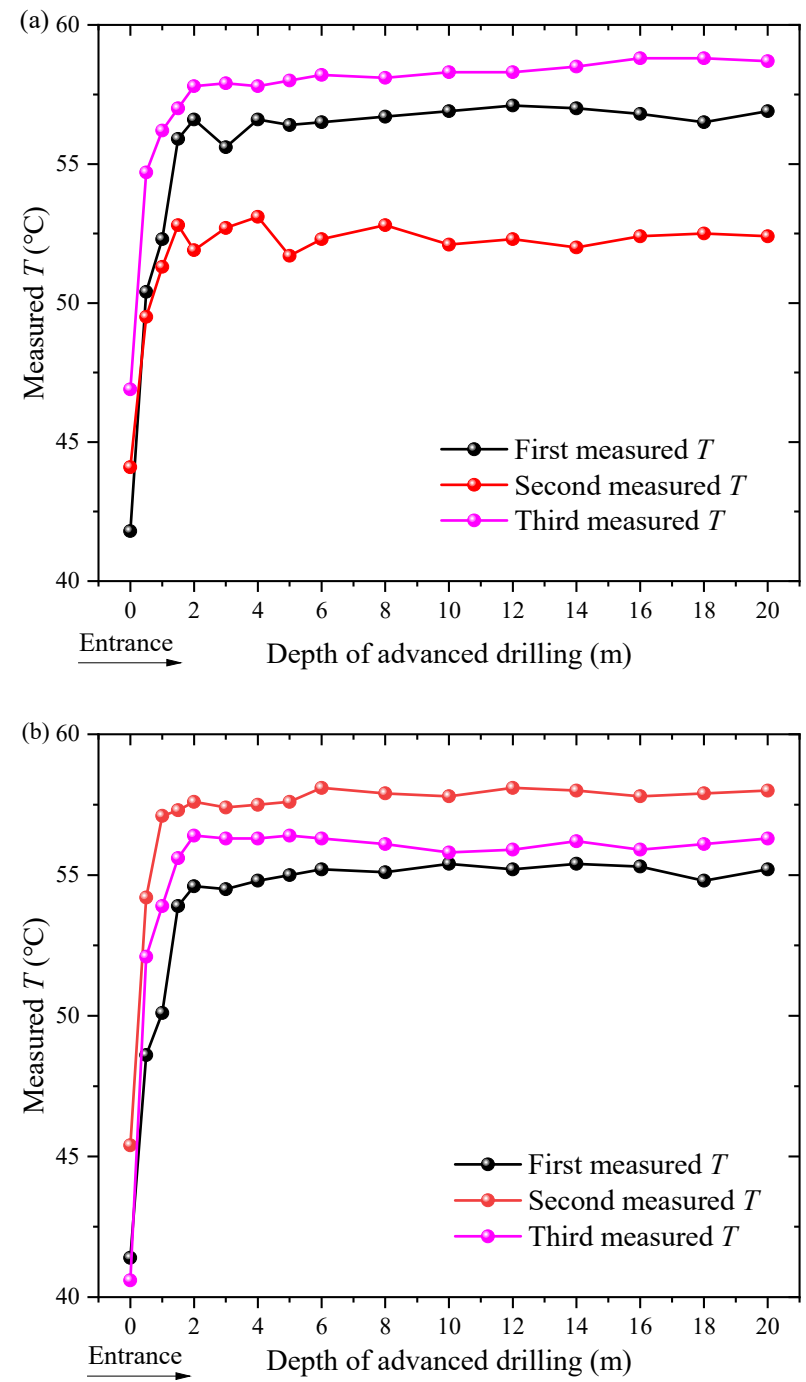

Figure 9. Matrix diagrams of the rock temperature change curve of three advanced drillings, in which $\mathrm{T}$ is the abbreviation for temperature: (a) left tunnel; (b) right tunnel.

\section{Discussion}

\subsection{The Mathematical Relationship between the Temperature and the Time during Construction}

Near the tunnel face, the air temperature of the tunnel construction area was tested continuously for six construction cycles, with a total number of measured temperature values of about 2200. The data were monitored from 2 June 2020 to 5 June 2020. Since the sixth cycle did not have complete data, only the data of the first five cycles are shown in Figure 10. The data presented in Figure 10 represent a total test duration of about $53 \mathrm{~h}$. Figure 10 presents the variation curves of the air temperature in each construction cycle. It can be seen that the maximum air temperature was $50.5^{\circ} \mathrm{C}$ and the minimum air temperature was $39.6{ }^{\circ} \mathrm{C}$ during the monitoring period. The temperature curves in each construction cycle show the features of decline: first a sudden rise, a second rise, and then a slow drop. The first decline of the air temperature corresponded to the drilling construction link. The drilling construction link is mainly affected by deterministic factors, such as ventilation and watering. The variation trends of each construction cycle were similar in the drilling construction link, and the air temperature dropped by $3-7^{\circ} \mathrm{C}$. Secondly, the first sudden rise in the air temperature corresponded to the blasting construction link. During the blasting construction link, the air temperature increased sharply in a short period of time, with a rising value of approximately $4-6{ }^{\circ} \mathrm{C}$, but the duration was short. Thirdly, the second sudden rise in the air temperature corresponded to the heat dissipation link of the 
surrounding rock. The heat dissipation of the surrounding rock after blasting also led to a sudden rise in the air temperature, which was smaller than that in the blasting construction link but lasted for a long time. Fourthly, the stage of the slow drop in the air temperature corresponded to the slag-out construction link. The change in the air temperature during slag-out construction was relatively complex, and there were some high, abnormal values. In the initial stage of this link, the air temperature increased to a certain extent due to the influence of the waste heat of the blasting and the heat dissipation of the surrounding rock. After cooling measures, such as ventilation, watering, and smoke exhaust, the air temperature gradually decreased. However, due to the influence of mechanical operations, such as slag-out of vehicles and operation of excavators, the air temperature showed several high and abnormal values. For example, the air temperature suddenly increased by $2-3{ }^{\circ} \mathrm{C}$.

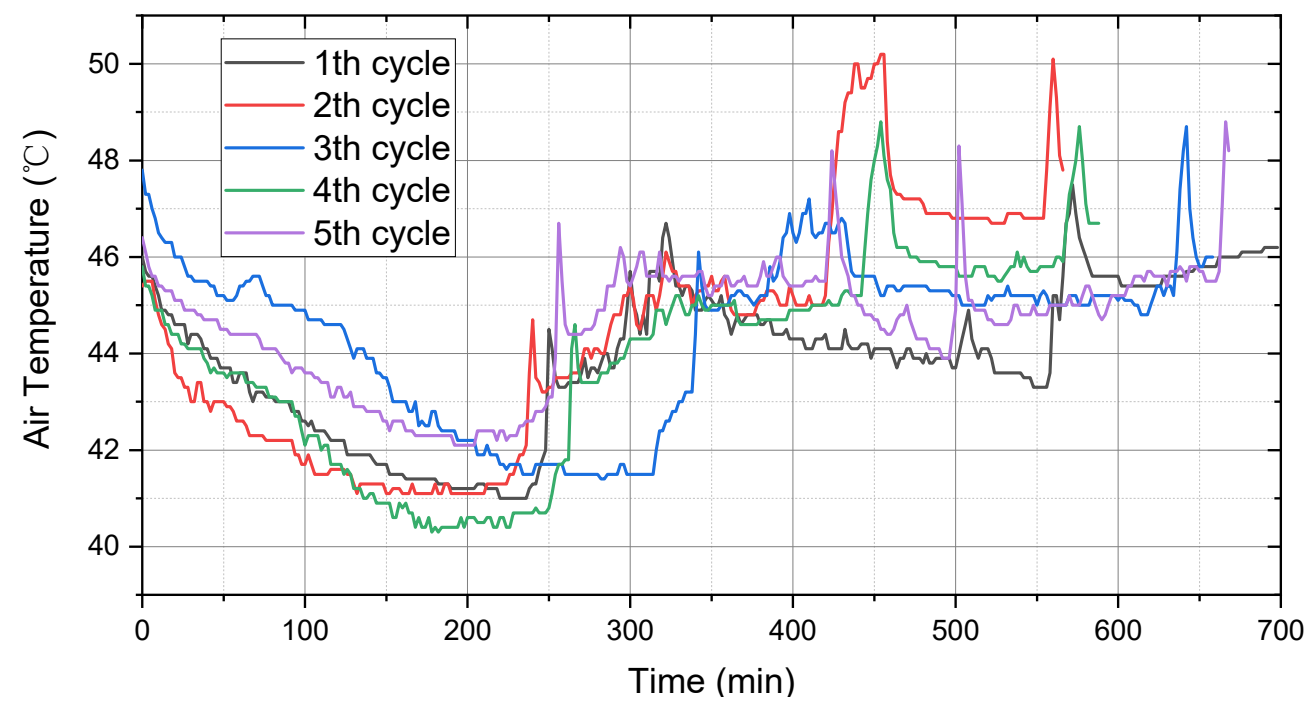

Figure 10. Temperature variation curves of each construction cycle.

\subsection{Mathematical Model of the Air Temperature and the Time during Construction}

According to the abovementioned analysis, the variation law of the air temperature with the time during construction can be summarized as a generalized model, as shown in Figure 11. The model can be divided into four stages. The first stage is the drilling construction link, which corresponds to the region of $t_{0}-t_{1}$ in the temperature-time curve. In this stage, the air temperature shows a linear decreasing trend with time. The second stage is the blasting construction link, which corresponds to the region of $t_{1}-t_{2}$ in the temperature-time curve. In this stage, the air temperature shows a sudden rise with time. The Boltzmann function can be used to describe the temperature-time relationship of the second stage more accurately. The first stage lasts for a short time, and the air temperature decreases suddenly after a certain sudden increase. The third stage is the heat dissipation link of the surrounding rock, which corresponds to the region of $t_{2}-t_{3}$ in the temperaturetime curve. In this stage, the heat dissipation of the newly exposed surrounding rock, which has a high temperature, occurs after blasting. Simultaneously, the Boltzmann function can also be used to describe the temperature-time relationship of the third stage more accurately. Finally, the fourth stage is the slag-out construction link, which corresponds to the region of $t_{3}-t_{4}$ in the temperature-time curve. This stage is more obviously affected by mechanical operations, and the air temperature has many high, abnormal values. However, the temperature shows a linear and slow decreasing trend with time after eliminating the abnormal values. 


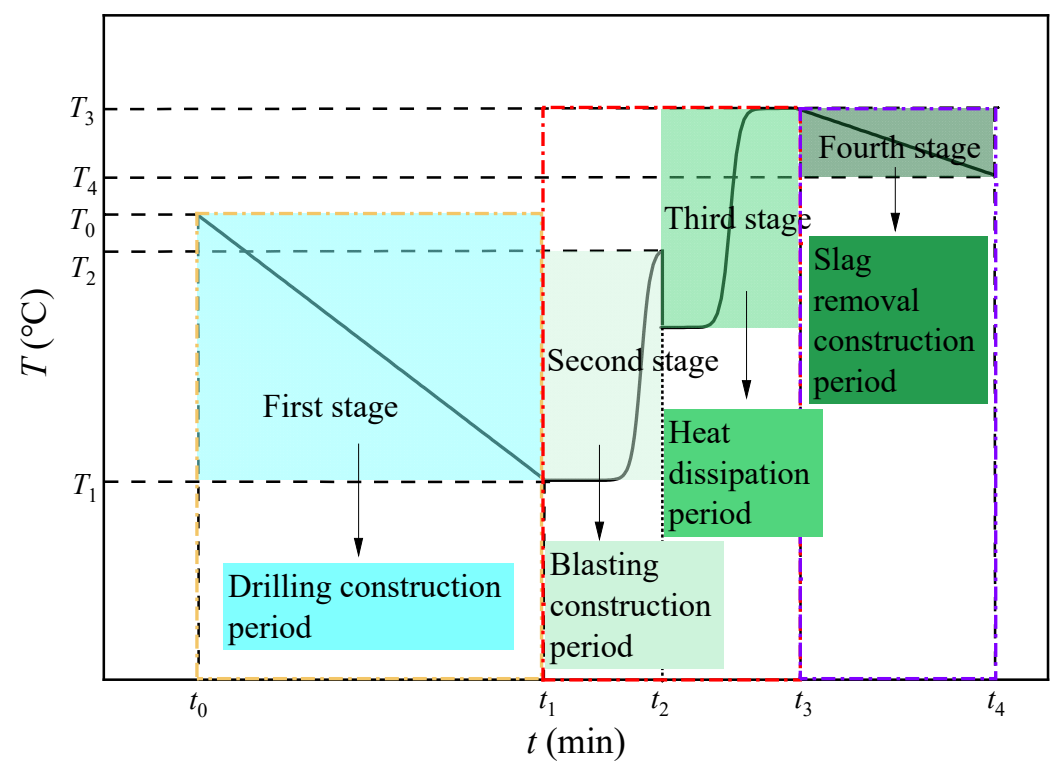

Figure 11. Model diagram of the temperature versus the time in a construction cycle.

Based on the generalized model characteristics above, the air temperature during construction showed specific variation trends in each construction stage. Specifically, each stage presented different variation laws, so different mathematical expressions can be used to characterize these laws. Ignoring the effect of mechanical operations on the temperature, the temperature-time mathematical relationships during tunnel construction can be expressed as:

$$
\left\{\begin{array}{l}
T=a_{1} t+b_{1}\left(t_{0} \leq t \leq t_{1}\right) \\
T=\frac{m_{\min }-m_{\max }}{1+e^{\left(t-t_{\mathrm{m}}\right) / d t_{\mathrm{m}}}}+m_{\max }\left(t_{1} \leq t \leq t_{2}\right) \\
T=\frac{n_{\min }-n_{\max }}{1+e^{\left(t-t_{\mathrm{n}}\right) / d t_{\mathrm{n}}}}+n_{\max }\left(t_{2} \leq t \leq t_{3}\right) \\
T=a_{2} t+b_{2}\left(t_{3} \leq t \leq t_{4}\right)
\end{array}\right.
$$

where $T$ is the ambient temperature during tunnel construction; $t$ is the construction time; $a_{1}$ and $b_{1}$ are the slope and intercept of the linear function in the first stage, respectively; $m_{\min }$ and $m_{\max }$ are the minimum and maximum air temperature in the second stage in the Boltzmann function, respectively; $t_{\mathrm{m}}$ is the $t$ value that corresponds to the value when the function $\mathrm{y}=\left(m_{\min }+m_{\max }\right) / 2$ holds at the second stage, and the value is close to the blast initiation time; $n_{\min }$ and $n_{\max }$ are the minimum and maximum air temperature in the third stage in the Boltzmann function, respectively; $t_{\mathrm{n}}$ is the $t$ value that corresponds to the value when the function $\mathrm{y}=\left(n_{\min }+n_{\max }\right) / 2$ holds at the third stage, and the value is a short time after the blasting; and $d t_{\mathrm{m}}$ and $d t_{\mathrm{n}}$ are the values of the Boltzmann function at the second and third stages, respectively, which characterize the rapid and slow physical quantities of the sudden rise in the air temperature. Both $d t_{\mathrm{m}}$ and $d t_{\mathrm{n}}$ are calculated by $\left(t_{(\mathrm{m}, \mathrm{n}) \max }-t_{(\mathrm{m}, \mathrm{n}) \min }\right) / 20$. Finally, $a_{2}$ and $b_{2}$ are the slope and intercept of the linear function in the fourth stage, respectively.

Reliable rock temperature prediction is important in hot and dry environments or hot and humid environments. In these environments, construction personnel experience reduced work efficiency, and mechanical equipment has a reduced service life. The temperature-time mathematical relationships during the Nige tunnel construction can be used to predict tunnels with similar working conditions. For tunnels with a similar heat source, lithology, and structural conditions as the Nige tunnel, the proposed model may be used to predict the temperature change in the process of tunnel construction to a certain extent. Calibration of the different parameters in the generalized model should be performed for new, unknown deep tunnels. In addition, an artificial neural network 
model could also be developed to predict the geotemperature during tunnel construction. However, this work has some limitations. Firstly, this study only considered monitoring data for a certain section during tunnel construction and lacks monitoring data for the whole tunnel construction period, especially during tunnel operation. Secondly, without having monitoring data of the geotemperature for many years, it is impossible to predict the variation laws of the geotemperature in different periods. Finally, the model proposed in this paper is only applicable to specific times and specific working conditions.

\section{Conclusions}

(1) The Nige tunnel can be considered a typical deep-buried extra-long tunnel with a high water temperature and high rock temperature. Based on the investigation and monitoring of the tunnel, the maximum water temperature was $63.4{ }^{\circ} \mathrm{C}$, the maximum rock temperature was $88.8^{\circ} \mathrm{C}$, and the maximum air temperature was $56.4^{\circ} \mathrm{C}$.

(2) Through the analysis of the geotemperature measurement data, it was found that in the limestone section, the phenomenon of the high water temperature was prominent. The water temperature was higher than the air temperature, and the rock temperature was the minimum. Both the water temperature and the air temperature showed upward trends with the horizontal distance and the buried depth of the tunnel. Besides that, both the flow of the water and the water temperature reached high values near the contact zone. The air temperature of the tunnel is greatly affected by the water temperature, the flow of the water and the tunnel ponding. In the granite section, the phenomenon of the high rock temperature was prominent, and no water was exposed. Additionally, both the rock temperature and the air temperature with the tunnel's horizontal distance and the buried depth showed an increasing trend, and the difference between them was about $25-30{ }^{\circ} \mathrm{C}$, and the geotemperature gradient was approximately $7.6^{\circ} \mathrm{C}$ per $100 \mathrm{~m}$.

(3) The variation laws of the construction ambient temperature with the time in a complete construction cycle presents four stage characteristics, including the drop stage that corresponds to the drilling construction link, the sudden rise stage that corresponds to the blasting construction link, the second rapid rise stage that corresponds to the heat dissipation of the newly blasted surrounding rock, and the slow drop stage that corresponds to the slag out construction link. Therefore, the Nige tunnel is a typical high geotemperature engineering case. This study has a guiding significance for the tunnel construction in the high geotemperature area in Southwest China.

Author Contributions: Conceptualization, T.W., Z.H. and J.S.; methodology, T.W. and Z.H.; validation, Y.W. and Z.Z.; investigation, Z.H.; data curation, Z.H.; writing-original draft preparation, T.W. and Z.H.; writing-review and editing, T.W.; funding acquisition, T.W. and Z.H. All authors have read and agreed to the published version of the manuscript.

Funding: The work was funded by the National Natural Science Foundation of China (No. 42002268); Open Foundation of Hubei Key Laboratory of Blasting Engineering (HKLBEF202012); Guizhou Province Science and Technology Plan Project (Project Number: Oiankehe Platform Talent (2019) No.5301); Cooperative Innovation Center of Unconventional Oil and Gas (Ministry of Education \& Hubei Province) (UOG2020-11); Open Foundation of Engineering Research Center of Rock-Soil Drilling \& Excavation and Protection, Ministry of Education.

Institutional Review Board Statement: Not application.

Informed Consent Statement: Not application.

Data Availability Statement: The data that support the findings of this study are available in this study.

Conflicts of Interest: The authors declare no conflict of interest. 


\section{References}

1. Zhang, L.Y.; Mao, X.B.; Lu, A.H. Experimental study on the mechanical properties of rocks at high temperature. Sci. China Ser. E Technol. Sci. 2009, 52, 641-646. [CrossRef]

2. Chen, G.Q.; Li, T.B.; Zhang, G.F.; Yin, H.Y.; Zhang, H. Temperature effect of rock burst for hard rock in deep-buried tunnel. Nat. Hazards 2014, 72, 915-926. [CrossRef]

3. Zeng, Y.H.; Tao, L.L.; Ye, X.Q.; Zhou, X.H.; Fang, Y.; Fan, L.; Liu, X.R.; Yang, Z.X. Temperature reduction for extra-long railway tunnel with high geotemperature by longitudinal ventilation. Tunn. Undergr. Space Technol. 2020, 99, 103381. [CrossRef]

4. Guo, Q.H. Hydrogeochemistry of high-temperature geothermal systems in China: A review. Appl. Geochem. 2012, 27, 1887-1898. [CrossRef]

5. Meng, W.; He, C. Back analysis of the Initial geo-stress field of rock masses in high geo-temperature and high geo-stress. Energies 2020, 13, 363. [CrossRef]

6. Ozgener, O.; Ozgener, L.; Tester, J.W. A practical approach to predict soil temperature variations for geothermal (ground) heat exchangers applications. Int. J. Heat Mass Tran. 2013, 62, 473-480. [CrossRef]

7. Kästner, F.; Giese, R.; Planke, S.; Millett, J.; Flóvenz, Ó.G. Seismic imaging in the Krafla high-temperature geothermal field, NE Iceland, using zero- and far-offset vertical seismic profiling (VSP) data. J. Volcanol. Geoth. Res. 2020, 391, 106315. [CrossRef]

8. Hu, Y.P.; Wang, M.N.; Wang, Q.L.; Liu, D.G.; Tong, J.J. Field test of thermal environment and thermal adaptation of workers in high geothermal tunnel. Build. Environ. 2019, 160, 106174.

9. Qarinur, M.; Ogata, S.; Kinoshita, N.; Yasuhara, H. Predictions of Rock Temperature Evolution at the Lahendong Geothermal Field by Coupled Numerical Model with Discrete Fracture Model Scheme. Energies 2020, 13, 3282. [CrossRef]

10. Shankar, V.K.; Kunar, B.M.; Murthy, C.S.N. ANN model for prediction of bit-rock interface temperature during rotary drilling of limestone using embedded thermocouple technique. J. Therm. Anal. Calorim. 2020, 139, 2273-2282. [CrossRef]

11. Dwivedi, R.D.; Goel, R.K.; Prasad, V.V.R.; Sinha, A. Thermo-mechanical properties of Indian and other granites. Int. J. Rock Mech. Min. 2008, 45, 303-315. [CrossRef]

12. Ortlepp, W.D.; Stacey, T. Rockburst Mechanisms in Tunnels and Shafts. Tunn. Undergr. Space Technol. 1994, 9, 59-65. [CrossRef]

13. Vacek, J.; Chocholoušová, J. Rock Burst Mechanics: Insight from Physical and Mathematical Modelling. Acta Polytech. 2008, 48, 1-7. [CrossRef]

14. Kaiser, P.K.; Cai, M. Design of rock support system under rockburst condition. J. Rock Mech. Geotech. Eng. 2012, 4, $215-227$. [CrossRef]

15. Rybach, L.; Busslinger, A. Verification of rock temperature prediction along the Gotthard base tunnel-A prospect for coming tunnel projects. In Proceedings of the World Tunnel Congress, Geneva, Switzerland, 31 May-7 June 2013; pp. 1-8.

16. Zhou, F.Z.; Xiong, Y.C.; Tian, M. Predicting initial formation temperature for deep well engineering with a new method. J. Earth Sci. 2015, 26, 108-115. [CrossRef]

17. Yang, S.Q.; Ranjith, P.G.; Jing, H.W.; Tian, W.L.; Ju, Y. An experimental investigation on thermal damage and failure mechanical behavior of granite after exposure to different high temperature treatments. Geothermics 2017, 65, 180-197. [CrossRef]

18. Cui, S.G.; Liu, P.; Cui, E.Q.; Su, J.; Huang, B. Experimental study on mechanical property and pore structure of concrete for shotcrete use in a hot-dry environment of high geothermal tunnels. Constr. Build. Mater. 2018, 173, 124-135. [CrossRef]

19. Lau, J.S.O.; Jackson, R. The effects of temperature and water-saturation on mechanical properties of Lac duBonnet pink granite. In Proceedings of the 8th International Congress on Rock Mechanics, Tokyo, Japan, 25-29 September 1995; pp. 1167-1172.

20. Lin, Q.X.; Liu, Y.M.; Tham, L.G.; Tang, C.A.; Lee, P.K.K.; Wang, J. Time-dependent strength degradation of granite. Int. J. Rock Mech. Min. 2009, 46, 1103-1114. [CrossRef]

21. Lan, H.X.; Martin, C.D.; Andersson, J.C. Evolution of in situ rock mass damage Induced by mechanical-thermal loading. Rock Mech. Rock Eng. 2013, 46, 153-168. [CrossRef]

22. Wang, M.N.; Hu, Y.P.; Wang, Q.L.; Tian, H.T.; Liu, D.G. A study on strength characteristics of concrete under variable temperature curing conditions in ultra-high geothermal tunnels. Constr. Build. Mater. 2019, 229, 116989. [CrossRef] 